\title{
The Role of Local Government Authorities in Facilitating Land Access for Small and Medium Tourism Enterprises Growth in Tanzania
}

\author{
Sanga D A Tonya E M and Chachage B L C
}

\begin{abstract}
The sustainable development of tourism destinations relies much on Small and Medium Tourism Enterprises found within Local Government Authorities (LGAs). However, tourism destinations have recently being experiencing an increase of population and social economic activities. This situation creates more demand of the land among stakeholders in particular tourism business. Contrary to lager tourism companies Small and Medium Enterprises(SMTEs) has found to be in a less advantageous position in acquiring land from destination which impairing their growth. Thus, land at the destinations is often regarded as one of the constraints for tourism development. The purpose of this study therefore was to examine the role of Local Government authorities in facilitating land management in tourism destinations particularly considering the effects upon the SMTEs growth. The study was guided by stakeholders' theory. Using census survey design 232 questionnaires were collected from SMTEs owners/managers at Mto wa Mbu ward in Monduli District. Multiple linear regression was used to determine the relationship between the dependent variable, SMTEs growth and five independent variables. The results strongly confirm the put forward hypothesis "Local government Authorities role in facilitating management of land interests has statistically positive influence on SMTEs growth", Moreover, five independent variables: land committee, by- law, land allocation, land law and Land policy have statistically significant impact on the growth of small business. Therefore, the theoretical and practical implications of this study refer to stressing the need and important role of LGA's in managing stakeholders land interests for local tourism that can stimulate the growth of small business within the destination. The study recommends empowerment of Local government Authorities in terms of legal framework to be part in the management regime of local tourism for sustainable development.

Keywords: Tourism, SMTEs growth, land policy, Land allocation
\end{abstract}

DOI: $10.7176 / \mathrm{JAAS} / 67-04$

Publication date:August $31^{\text {st }} 2020$

\subsection{Introduction}

Tourism is arguably the world's largest and fastest growing industry (UNWTO, 2017). The sector accounts for about $17 \%$ of the world's Gross National Product and 9\% of the employment (WEF, 2018; CWTTC, 2017). In Tanzania, tourism accounts for 3.8\% of the GDP and generates nearly $30 \%$ of the country's total export earnings (NBS, 2017). The sector also in Tanzania, employs directly around 600,000 (4.3\%) people through small and medium enterprises (SMTEs) where some of them are related to large tourist enterprises and up to two million people indirectly (WTTC, 2017).

Like any other economic sector, tourism practices involve large companies and Small and Medium Enterprises in various destinations. According to the UNWTO it is majority of Local community who engage in tourism economy through SMTEs by offering various goods and services to the incoming tourists (UNWTO, 2017). Some of SMTEs includes Restaurants, Lodges, currier services, information canter services, art-crafts, transporters and tour guide services (Mganda et al, 2013). Therefore, understanding how SMTEs operates, challenges and success is the critical to maintain the quality of a destinations and tourism development.

The huge presence of SMTEs in tourism sector makes scholars curiosity on reviewing various aspects related to their operations in the tourism destinations. For instance, in terms of increasing the importance of small business for the recovery and growth of world economy (Othman and Rosili, 2011), growth of small businesses imposes itself as a relevant and important research area (Tundui, 2012). Additionally, the high failure rate, i.e. mortality of small businesses, increases the interest towards overcoming issues related to growth of small business.

Okello and Novelli (2014) reported that, challenges affecting the potential for tourism to flourish include political stability and governance, infrastructure development, service standards, and human capacity just to name a few. Wang and Liu (2013) added that one of reoccurring critical challenge faced by SMTEs is the access to the land for their business operations in the tourist's destinations. This is due to the fact that most tourism project and business activities are land driven usage. Land is important to SMTEs for residential buildings and office for carrying on tourism activities.

Successful countries in tourism such as China, Turkey and South Korea have widely acknowledged local tourism management by allowing local government authorities to be part in the management process of the destinations (Brokaj, 2014; OECD,2017). For instance, in China, previous tourism sector had difficulties when bargaining for land. However, the growing importance of the tourism economy and various stakeholders' demand 
for local tourism management impetus the reform to the sector. The government embarked on formulating policies to support local tourism including land usage. As a result, tourism projects had an opportunity to be recognized as provincial priority projects.

Likewise, an experience from Turkey has also shown that tourism business was more enhanced after being devolved planning and coordination of tourism activities at the grassroot level (Can et al, 2016). According to the research findings, the existence of proper land allocation lead to more opportunities for tourism investment and encouraged participation of more local peoples in small tourism business operations (Can ibid).

Similarly, in south Korea, Kim (2013) found that the growth oriented regional and local government policies over, small and medium scale tourism enterprises enabled local communities to have more voice in government planning and policy as the results more tourism enterprises' responsibility towards sustainable tourism development was realized. Whether or not tourism destinations are considered attractive by tourists depends to a large degree on how land is used. In this case OECD, (2017) argues that local planning is needed to co-ordinate stakeholder's investment decisions at the destinations.

Access to land is a crucial prerequisite for tourism business. Land is needed for tourism infrastructure and facilities, and for tourism-associated businesses and services (ADB, 2015). In Tanzania, many tourism destinations are now experiencing limited land area due to various activities undertaking including tourism. The rapid increasing population, and economic activities such as farming and livestock keeping and tourism resulted to the struggling in acquiring of land among the stakeholders (URT,2015). Furthermore, tourism activities necessitated other necessary services which affect land usage such as investments on real estates and social services like roads. (Muganda et al, 2013; Mitekaro, 2016). Given this continuous land competition within tourism destinations SMTEs has found to be in more disadvantages regarding the accessibility to the land a situation which affects their operations.

In line with above, the government of Tanzania has been taking various efforts in addressing various challenges facing tourism sector. These includes efforts formulation of various policies and laws such as Decentralization by Devolution (D-by-D), National Tourism Policy of 1999 (URT, 1999), National Tourism Act of 2008 (URT, 2008). However, specifically problem of land shortage for tourism within the destination places has not been well addressed. This could be the reason for the sector being experiencing the slow growth and high failure rates of SMTEs (Sitts, 2010 and TPSF, 2010). The paper therefore argues that, in the land scarcity situation small and medium enterprises may not be able to access to the land like other giant companies within the destination.

The fact that many researches have been done on the Central government role in relation to community participation in tourism Sitts, 2010; Safari, 2015 and Mitekaro, 2016). There are still not much empirical evidence prevailing about the influence of local government role in managing stakeholders land interest on SMTEs growth within their area of jurisdiction.

Thus, the objective of this research was to examine the role of Local government Authorities in managing stakeholders' interest on land for Small and medium Tourism business within tourism destinations place in Tanzania. The research model is designed to test the impact of four potential LGAs' roles on land that could affect growth of small business, identified and selected using the stakeholder's theory and most relevant literatures of tourism and small business growth. Therefore, the theoretical and practical implications of this research refer to stressing need and important role of LGAs in managing stakeholders' land interests for local tourism that can stimulate the growth of small business within the destinations.

\subsection{Methods}

The research study was conducted at Mtowa Mbu Ward which comprises nine villages. The ward is found at Monduli district, Arusha region. The area's location supports tourism activities and it is found within the tourism nodes famous northern tourism circuit (Muganda et al., 2013). As such tourism situation have attracted and resulted to the establishment of many SMTEs who are targeted people for collecting the required information for the study.

The target population size of this study was 232 SMTEs owners registered tourism business as per Monduli District Council report of 2015/2016 (URT, 2016). Given the small population the study follows census survey approach in data collections. This is in line with Creswell, (2014) together with Singh and Masuku (2014) who argue that a census is more attractive for small population because it eliminate sampling errors and provide data on all individuals in the population.

A quantitative survey was deployed to collect primary data using structured questionnaires from ownermanagers of SMTEs. The study adopted a questionnaire of World Tourism Organization (2006) which seemed to be relevant to the study. Some questions were modified from questionnaire developed by Alshboul, (2016).

The data analysis involved data preparation, descriptive and inferential statistics. On the other hand, Coefficient of determination $\left(\mathrm{R}^{2}\right)$ was used to determine the goodness of fit of different models by indicating whether the proportion of SMTEs growth explained by all the combined predictor variables was equal, greater than or less than the population of each predictor variable. Regression analysis is a technique used to analyse the 
relationship between a single dependent variable and one or several independent variables (Byrene, 2013).

Multiple Regression Analysis was deployed to test hypothesis. The study hypothesised that the role of LGAs in facilitating community participation in tourism has significant contribution on SMTEs growth. Prior running regression Exploratory Factor Analysis was performed in order to ensure links between the observed and latent variables. Furthermore, correlation was deployed in order to check whether there is significant association among the study variables.

\subsection{Results}

\subsection{Social Economic Information of the Respondents}

In this study $42 \%$ of the total respondents were female while $68 \%$ of them were male. This gives an implication that more men are involved in tourism services than women. The findings are in line with the observation made by Baumus (2013) argument that men in tourism at work are more involving than women. The imbalance is presumed contributed by the fact that more women are engaged in other domestic responsibilities such as children caring, cooking for family and other family related activities. Due to cultural women are carrying more family responsibilities compared to men. Women are supposed wisely budget time of business and time for meeting home need such as to prepare food for breakfast, lunch and dinner. Furthermore, women have to take care children and other home activities at home. The observation also revealed that the majority of the women were engaged in petty economic activities like selling varieties fruits, vegetable and handcrafts to visitors. However, it is important to point out that the purpose of this study was not to make comparison of the men and women engaged in SMETs but to understanding the status level of the respondents of the study.

On the other hand, result from Table 3.1 shows that (42\%) SMTEs managers had completed a primary school while $41 \%$ of the respondents had finished secondary school level. The observation also revealed $11 \%$ of the respondents had College/University education level and the last group of respondents were $6 \%$ who had informal education only. These result patterns denote that most of the respondents had adequate education which has contributed in giving reliable and valid data to this current study. Having majority of the respondent's graduates of secondary school, it suggests that what was answered was known to them. This contribute in enhance the validity and reliability of findings.

Table 3.1: Demographic characteristics of the respondents

\begin{tabular}{lll}
\hline Variable & Frequency & Percent \\
Education level & 13 & 6.34 \\
Informal & 86 & 41.95 \\
Primary education & 84 & 40.98 \\
Secondary & 22 & 10.73 \\
College/University & & \\
Sex of respondent & 140 & 68.29 \\
Male & 65 & 31.71 \\
Female & & \\
Age of respondent & 109 & 53.17 \\
19-34 & 88 & 42.93 \\
35-54 & 8 & 3.90 \\
55 and above & & \\
Type of SMTEs & 52 & 25.49 \\
Canteen & 72 & 35.29 \\
Art gallery & 20 & 9.80 \\
Tour operators & 34 & 16.67 \\
Traditional culture performance & 26 & 12.75 \\
Others & & \\
\hline Source & & \\
\hline
\end{tabular}

Source: Field survey, 2018

\subsection{Descriptive Analysis}

The objective of this research was to examine the role of Local government Authorities in managing stakeholders' interest on land for Small and medium Tourism business within tourism destinations place in Tanzania. Therefore, management of stakeholder's land interest was measured by three items namely: Land allocation (LA), Land laws (LL) and Land policy (LP) as shown in Table 4.15 . Generally, about $17 \%$ of the respondents were on opinion that LGAs facilitation role in managing land interest does not promote SMTEs growth. In the other hand $47 \%$ of the respondents were in favor of LGAs that their role in managing stakeholders land interests has contribution to the growth of SMTEs. However, $36 \%$ of the respondents were in neutral stand regarding the role of LGAs in managing stakeholders land interest. The results imply that the involvement of LGAs in managing tourism in relation to land is crucial for fostering the growth of SMTEs within the destination. 
Table 4. 1 Descriptive statistics of LGA in Managing Stakeholders' land Interest

\begin{tabular}{|l|l|l|l|l|l|l|l|l|l|l|l|l|}
\hline & \multicolumn{2}{|l|}{ Strong disagree } & Disagree & Cumm Disagree & \multicolumn{2}{|l|}{ Neutral } & \multicolumn{2}{|l|}{ Agree } & \multicolumn{3}{|l|}{ Strong agree } & Cumm Agree \\
\cline { 2 - 13 } & $\mathrm{N}$ & $\%$ & $\mathrm{~N}$ & $\%$ & $\%$ & $\mathrm{~N}$ & $\%$ & $\mathrm{~N}$ & $\%$ & $\mathrm{~N}$ & $\%$ & $\%$ \\
\hline LA & 16 & 8 & 33 & 16 & $\mathbf{2 3 . 9}$ & 56 & 27 & 95 & 46 & 5 & 3 & $\mathbf{4 8 . 7}$ \\
\hline LL & 4 & 2 & 20 & 10 & $\mathbf{1 1 . 8}$ & 76 & 37 & 98 & 48 & 7 & 3 & $\mathbf{5 1 . 2}$ \\
\hline LP & 5 & 2 & 27 & 14 & $\mathbf{1 5 . 6}$ & 89 & 43 & 78 & 38 & 6 & 3 & $\mathbf{4 0 . 9}$ \\
\hline
\end{tabular}

Source: Researcher (2019)

\subsection{Hypothesis testing}

Little is known about the contribution of Local government authorities' role in managing destination towards the growth of SMTEs. In order to confirm the influence of LGAs role in managing stakeholders land interests for SMTEG growth, the following hypothesis was developed as stated below: Local Government Authorities' role in facilitating management of land interest has statistically positive influence on SMTEs growth.

The stated hypothesis above was tested using Multiple Regression Analysis. The results demonstrate positive and significant relationship between LGAs' roles on facilitating stakeholders land interest for SMTES growth in Tanzania. This is because $p$ - values is found being within the range which is less $0.05(\beta=.197, t=2.697, p=.008)$ as shown in Table 3:3. These findings confirm that, there is positive and significant contribution between the LGAs' role in managing stakeholders' land interest on SMTEs growth in Tanzania. Therefore, the stated hypothesis is accepted. These study's findings imply that the growth of Small business depend much when Local government authorities effectively manage stakeholders' interest on land at the destination.

Table 3.3 Regression model summary

\begin{tabular}{|c|c|c|c|c|c|c|c|c|c|c|c|}
\hline & \multicolumn{2}{|c|}{$\begin{array}{l}\text { Un standardized } \\
\text { coefficients }\end{array}$} & \multirow{2}{*}{ 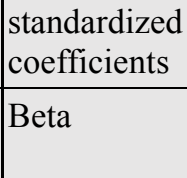 } & \multirow[t]{2}{*}{$\mathrm{t}$} & \multirow[t]{2}{*}{ Sig } & \multicolumn{3}{|c|}{ Correlations mode } & \multicolumn{2}{|c|}{$\begin{array}{l}\text { Collinearity } \\
\text { statistic }\end{array}$} \\
\hline & & $b$ & Std Error & & & & $\begin{array}{l}\text { Zero- } \\
\text { order }\end{array}$ & partial & part & tolerance & VIF \\
\hline \multirow[t]{2}{*}{1} & (Constant) & 3.819 & .679 & & 5.621 & .000 & & & & & \\
\hline & LI & .153 & .057 & .197 & 2.697 & .008 & .304 & .187 & .175 & .785 & 1.274 \\
\hline
\end{tabular}

\subsection{Discussion}

Land usage in tourism sector draws major interests among the resources needed by destinations stakeholders. Both Small business owners and larger tourism enterprises need a certain size of peace of land that will enable to place their operations. In the other hand, there continuous economic apart from tourism sector activities of which land stand as a prime motive such as agricultures and livestock keeping, industries and urbanization. All these activities undertaking at the tourism destinations draws interests and more attention on land usage among stakeholders. in this situation facing tourism the role of LGAs in managing the scarce land while balancing multiple stakeholders' interests on land usage cannot be over emphasized.

In this respect the objective of the study aimed to examine the influence of LGAs' role in managing tourism stakeholders' land interest on SMTEs growth. To achieve the objective, it was prior hypothesized: that Local Government' role in managing stakeholders' land interest has statistically positive influence on SMTEs growth. The empirical result Table 3.3 above supported the above hypothesis with the following regression coefficients $(\beta$ $=.197, t=2.697, p=.008$ ). Therefore, from the statistical results signify that the LGAs' supportive efforts in managing stakeholder's interest on land have positive significant influence in SMTEs growth Tanzania. Therefore, the stated hypothesis was accepted.

The above statistical results were supported by descriptive statistical analysis which was run to profile the impacts of each measurements item of Land allocation, Land laws and Land policy. The results showed that overall $47 \%$ of respondents were on opinion that the role of LGAs in managing stakeholders land interest has contribution towards the growth of SMTEs. The descriptive results suggest that the overall LGA's roles in managing stakeholder's interest on land usage in their area of jurisdiction are paramount and influence the growth of SMTEs in Tanzania.

Therefore, results support the argument made on stakeholders' theory which insist the importance of tourism destination planner to ensure stakeholders interest on tourism resources are carefully managed so that the tourism destination realize its sustainable tourism development (Prabhakarana et al, 2014).

Generally, the study's results of regression and descriptive analysis were found that all three assumed items 
of stakeholder's land interest namely Land allocation, Land laws, Land policy have been found to be significant influential. This implies that the LGAs facilitation roles hold true in supporting local tourism hence growth of SMTEs. Each stakeholder 'interests' item is discussed in the subsequently sections.

\subsection{Land Policy formulation for SMTEs growth}

Recently, there is pushing for local policy formulation on land usage in many tourism destinations. The outcry for local policy formulation comes from various tourism stakeholders who believe that tourism sector is not giving equal weight in land usage compared to other sector such as agriculture. Rong (2008) argued that many innovative policies to meet local needs are initiated by local governments and then accepted by the central government. This is especially true for land policies, which are mainly pushed by the local governments and then the central government formulates land policies to respond to these local needs, such as increasing land quotas and loosening administrative control ( $\mathrm{Li}$, et al, 2010).

In this study finding has been confirmed that local land policy formulation to be among the items comprises land management for tourism that has a strong and positive influence on SMTEs growth within the destination. The findings confirmed the assumption put forward by the study that if LGAs facilitates policy formulation on the local land policy in favour of tourism, it can have a bearing effect on the SMTEs growth.

However, the findings of the study contradict with the study findings put forward by Nelson (2005) in Masai land in Tanzania. Nelson found that in local tourism places there is lack of clear land policy which attributed to continuation of land tension among stakeholders especially local community. The study further found that the evictions of local community in the land which has been declared as public protected area for tourism has resulted to competing of land among stakeholders. The study argued the establishment of local land policy formulation to protect the interest and need of both government and community. This means still the role of local government in managing tourism in their area of jurisdiction is paramount important.

The study's findings are similar to the study done in China by $\mathrm{Xu}$, et al. (2017). the study established that rapid growth in tourism development resulted to increasing demands for land use, thus some planned tourism projects might not be carried out as a result of lack of local land policy. This signify that land policy formulation address stakeholders need and interest is imperative things for the tourism destination to achieve its objective. The local land policy will minimize and address challenges and all possible conflict that might occurs due to land competing among the stakeholders. This gives credence to the stakeholder's theory as well regarding local governance and meeting need and interest of stakeholders in achieving goals of the tourism development of local tourism. Generally, the study findings establish that instead of central government being formulating various policies including land policy also there is a need for local government to engage and formulating local land policy that for the sustainable development of local tourism.

\subsection{Land Allocation for SMTEs growth}

The findings from regression analysis has confirmed that proper land allocation to stakeholders is among the roles of LGAs that influences the growth of SMTEs. This was inline with descriptive results which shows that $50 \%$ of the respondents were on opinion that the tourism sector within the destinations need special allocation of land to enable stakeholders carry on their activities. The implication is that Local Government Authorities (LGAs) are very important organ in managing stakeholders' interest on land within the destination. LGAs have power to provide the political stability, security, and the legal and financial frame- work which tourism requires land should be.

The study's results support the stakeholder's theory which emphasis the important of managing stakeholders' interest in order the destination to achieve its sustainable developments (Jamal and Stronza, 2009). The findings further match with the findings of Okello \& Novell (2014) in East African countries. Okello noted that tourism in east African countries is rarely prioritized in government policies mainly due to a lack of understanding of how tourism works. This means that tourism destination needs effective management organ with full tourism knowledge and skills of which understand the respectively local environments.

In the other hand the findings contradict with situation observed s in Iran by Zarkesh et al. (2011) which indicated that there is an existing problem of land for ecotourism development. The study revealed that the shortage of land within the destinations was attributed by failure of the local government authorities to reserving land for tourism development purpose. From the findings it appears that many local governments are constraints with land capacity to handle and match with tourism development demand. A key point to note from these findings is that land allocations at the destination must be careful taking care by including stakeholders during the process. However, the obvious challenge that is vivid facing LGAs in particular council and villages is absence of tourism specialist that may take care and ensure tourism issues are taken in board during the planning and budgeting process. 


\subsection{Land laws for SMTEs growth}

The study's findings as shown in sections 3.2 and 3.3 have revealed that land law is among of the key factors for LGAs process in managing stakeholders' land interest for SMTEs growth. This implies that the land law has to reflect tourism development and favors stakeholders for the purposes of enhancing the growth of SMTEs within the destination. Furthermore, local land at the destinations need appropriate tourism governance structures within LGAs backed up with land laws.

The findings correspond with the finding of Abuharris and Ruddock (2015) in Libya which found that the advancement of local tourism was the results of reformation of policy and land law. Land reformation in Libya which allowed tourism stakeholders to access destination land enhanced various tourism projects in turn resulting to an increase of tourists in various destination. In Tanzania at present the existing land laws may not be strong enough to support tourism development. However, the amendment of land laws to reflects tourism aspects became essential for fostering the growth of SMTEs for achieving tourism sustainable development.

Furthermore, the study's findings match with the study of Can et al, (2016) in Turkey. Their study found that there was insufficient public land allocation for the purpose of tourism due to inadequate participation Local authorities in land use planning. The finding furthermore shows that the existing law does not compel direct LGAs to assume the responsibilities on tourism sector. However, the major benefits to be gained from land law that reflects tourism is to manage and balance the interest of stakeholders. Effective local management of stakeholder's interest on land much depend upon the existing law which favored tourism development. and reduce unnecessary conflicts that may occurs in scrambling of the destination land social. Local land at the destination need appropriate structures backed up with land laws

\subsection{Conclusion}

The objective of the study was to examine the implication of the role of LGA in managing tourism stakeholders' land interest on the SMTEs growth. First the study performed factor analysis in order to reduce a large number of variables into identifiable components of interrelated variables finally only three related variables were retained for study analysis namely land allocation, land laws and land policy. Followed where the running Pearsons' product moment correlation to tests the relationship between the variables. The correlation results revealed that there is positive and significance relationship between land interests and the growth of SMTEs growth variables.

Then the hypothesis three was tested by multiple regressions analysis model and the findings revealed that there is positive statistically significant influence between management of stakeholder's interest on land and SMTEs growth. In the other hand the overall average score of the LGA's Role in Management of land interests was approximately to 3 with standard deviation (STD) of 0.74 . That means the effort of Local government role in facilitating management of stakeholders' interests on land was rationally carried out within the destination. Basing on the study findings and discussion it can be concluded that the involvement of LGAs in managing stakeholder's interest on land is important but moderately carried out.

The underperforming of LGAs in managing stakeholders' land interest is not healthier for the growth of SMTEs and local tourism sustainability in Tanzania. As it was evidenced from the literatures review and study findings that in recent years land becomes very scarce in tourism destination areas. This is due to an increases larger number of stakeholders including SMTEs and large companies of which land remains to be the prime interest resource for their business.

There are also ongoing land subdivisions to individual private properties and conversion of range lands to crop cultivation and subsistence use. All these add up the interests and demand for the land among the stakeholders at the destination. The land demand continues increasing more competition and silent conflicts among stakeholders. It is the argument of this research article that if this situation continues without deliberate efforts to rescue the situation the tourism image may be jeopardized within destinations and may impair tourism development.

Therefore, in this respect the study draws a general conclusion by giving out strong indication that LGAs has to be capacitated in order to manage land at its optimal capacity level for the destination sustainability. If not actively involved in facilitating land usage there comes an inevitable point when the Tanzania tourism destinations becomes saturated and reaches over-development the nature of tourism destinations. It is further concluded that land protection status for tourism destination and that it uses purpose and that it affects the decision of tourists to visit as well as the growth of SMTEs.

\subsection{Recommendation}

Tourism like any other sector in practice needs access to land with scenery, native plants and wildlife. In turn, land stakeholders need money to maintain their land and its natural resources. Here comes the importance of managing stakeholders land interest at the destination. The study has demonstrated that there is highly stakeholders' interest and need influences upon local land usage for tourism activities at the destination area. The study further revealed that existence of local land policy and respectively by law on land usage constitute strength on local authorities in supporting SMTEs growth. Therefore, in managing stakeholders land interest the study 
recommend that it is imperative that the LGAs has to be capacitated in terms of human resources and finance in order to formulate local land tourism policy, land planning for tourism and ensure there is land allocation and control over land use in the destination.

\section{References}

Alshboul, K. (2016). Assessing Local Community Involvement in Tourism Development around a Proposed World Heritage Site in Jerash, Jordan. Waterloo, Ontario, Canada: University of Waterloo

Brokaj, R. (2014). Local Government' roles in the Sutstainable Tourism of a Destination. European Scientific Journal November 2014 edition vol.10, No.31 ISSN: 1857 - 7881(Print) e - ISSN 1857- 7431 .

Byrne, B. M. (2013). Structural equation modeling with LISREL, PRELIS, an SIMPLIS: Basic concepts, applications, and programming. Psychology Press.

Can, A. S., Turker, N., and Alaeddinoglu, F. (2016). Local Authorities Participation in the Tourism Planning Process. Transylvanian Review of Administrative Sciences, , No. 41 E/2014, pp. 190-212.

Creswell, W. J. (2014). Reserach Design : Qualitative, Quantitative and Mixed Methods. London: SAGE Publications.inc.

CWTTC. (2017). Travel and Tourism Economic Impact . Council World and Tourism Council .

Jamal, T., and Stronza, A.(2009). Collaboration theory and tourism practice in protected areas:stakeholders, structuring and sustainability. Journal of Sustainable Tourism: Vol. 17, No. 2, March 2009, 169-18

Kim, S., Park, E., and Phandanouvong, T. (2014). Barriers to Local Residents ' Participation in Community- Based Tourism : Lessons from Houay Kaeng Village in Laos, 5.

Okello, M. M., and Novelli, M. (2014). Tourism in the East African Community (EAC): Challenges, opportunities, and ways foward. Tourism and Hospitality Research, Vol. 14(1-2) 53-66

Othman, P. and Rosli, M. (2011). The Impact of Tourism on Small Business Performance: Empirical Evidence from Malaysian Islands, International Journal of Business and Social Science 2 (1), pp.11-19

Li, M. F., Cao, Y., \& Wang, C. C. (2010). Analysis on the benefit game between central and local governments in thereform of direct top-down land administration system. 24(6),

Kipkeu, M. L., Samson, P., and James, W. M. (2014). Community Participation in Wildlife Conservation in Amboseli, 8(4), 68-75.

Prabhakarana, S., Naira, V., and Ramachandranb, S. (2014). Community participation in rural tourism: Towards a conceptual. Procedia Social and Behaviour Science, 144 ( 2014 ) 290 - 295.

Mitekaro, M. G. (2016). The Impact of Tourism in Tanzania on Community Development

Muganda, M., Sirima, A., and Ezra, P. M. (2013). The Role of Local Communities in Tourism Development. Kamla-Raj .

NBS. (2017). The 2016 International Visitors’ Exit Survey Report. National Beural of Statistics

Wang, J. and Liu, Y., 2013. Tourism-led land-use changes and their environmental effects in the southern coastal region of Hainan Island, China

WEF (2018) World Economic Forum: The Traveland Tourism Competitiveness Report: Reducing Barriers to Economic Growth and Employments Creation

Tundui, H. P. (2012). Gender and Small Business Growth in. University of Groningen, Groningen, the Netherlands:

URT. (2002). Small and Medium Enterprises Development Policy. United of Republic of Tanzania .

URT. (1999). Tourism policy 1999. The United Repulic of Tanzania .

URT. (2003). Small and Medium Enterprises Development Policy. United of Republic of Tanzania .

UNWTO (2017). Measuring Employments in the Tourism Industries Annual report 2014: Guide with Best Practices

Reinius S W (2016). Tourism Attractions and Land Use Interactions Case Studies from Protected Areas in the Swedish Mountain Region: Licentiate Thesis Stockholm University

Rong, Z. (2008). The game between central and local governments in policy change: A case study of China'sland policy (1978-2007)] (Doctoral dissertation). Fudan University, Shanghai.

Safari, J. (2015). Involvement in Tourism Activities and Perceived Benefits in. American Journal of Environmental Protection, pp. 120-126.

Sitts, S. (2010). Tourism and economic development in Tanzania Masters of Arts in Law and Diplomacy Thesis,. The Fletcher School. Tufts University. https:// www. google. com. au/search.

Singh A S and Masuku M B (2014). Sampling technique \& Determination of sample size in apllied statitistics research :An overview:International Journal economics, Commerce and Management : VolI, issue 11

TPSF. (2010). Supporting the Competitiveness of Tanzania Tourism Strategic Action Plan Executive Summary. Cluster Competative Program.

Xu H, Xiang Z and Huang x (2017) Land Policies, Tourism Projects, and Tourism Development in Guangdong : Journal of China Tourism Research, 2017 vol. 13, no. 2, 161-177 